\title{
A FITOTERAPIA E A HOMEOPATIA COMO PRĀTICAS MÉDICAS ALTERNATIVAS
}

\author{
Daisy Leslie Steagall Gomes ${ }^{1}$, Luzia Márcia Romanholi² \\ Maria Tereza Garcia de Souza²
}

STEAGALL-GOMES, D.L. et alii. A fitoterapia e a homeopatia como práticas médicas alternativas. Rev. Bras. Enf., Brasília, 38(3/4): 329-348,jul./dez. 1985

\begin{abstract}
RESUMO. Na tentativa de se conhecer a maneira pela qual a fitoterapia e a homeopatia são utilizadas como práticas médicas pela comunidade, é que este trabalho foi realizado. Os dados foram obtidos através de questionários e a população incluída foi de: alunos de habilitação de enfermagem de saúde pública e pessoas que se utilizam dos serviços médicos do INAMPS e do Centro de Saúde I de Ribeirão Preto, da Secretaria de Estado da Saú. de de São Paulo. Os resultados permitiram conhecer qual a aceitação e o quanto essas prá. ticas podem ser consideradas legitimadas e conhecidas pela população estudada.
\end{abstract}

\begin{abstract}
This study attempts to clarify the extent to which herbal medicine and homeopathy are accepted as medical treatment within the community. The data was obtained through questionaires; those questioned included students in the field of public health and nursing and those who use the medical facilities provided by INAMPS and the 'Centro de Saúde I' of Ribeirão Preto, under the Health Secretariat of the State of São Paulo. The results indicate the degree of acceptance and the extent to which these practices are considered legitimate within the population studied.
\end{abstract}

\section{INTRODUÇÃO}

A capacitação de recursos humanos para o desenvolvimento de ações de saúde para os serviços de assistência médiça à população é assunto de grande relevância e que, nos dias atuais, domina grande parte da preocupação dos que estão na área da saúde ou a ela se ligam de alguma forma.

O Ministério da Saúde (BRASIL. Ministério da Saúde $)^{1}$, falando do preparo do pessoal de nível auxiliar lembra que "o sistema institucional de saúde há muito vem procurando desenvolver programas de saúde que tentam obedecer. a alguns princípios, tais como: trabalhar com a comunidade, respeitar os valores da comunidade..."

Considerando essa premissa de se trabalhar com a comunidade respeitando seus valores e apro- veitando os recursos disponíveis como meio de satisfazer suas necessidades básicas, principalmente das populaçбes de países em desenvolvimento, é que torna o estudo das chamadas medicinas alternativas (aquelas que não fazem parte da chamada medicina oficial) oportuno e necessário.

Como foi anotado por NOGUEIRA 10 "a Organização Mundial de Saúde está se dando cada vez mais conta da importância e da utilidade dos sistemas de medicina tradicional embora, é claro, reconheça o alto nível de desenvolvimento da medicina moderna, principalmente após o advento dos antibióticos e das técnicas avançadas de cirurgia".

Da chamada medicina tradicional ou alternativa, destacamos duas delas: a fitoterapia e a homeopatia como sendo práticas utilizadas no Brasil.

No Brasil, por muito tempo, as plantas medici-

1. Professor Assistente da Escola de Enfermagem de Ribeirão Preto da Universidade de São Paulo.

2. Enfermeiras de Saúde Pública das Usinas de Açúcar e Álcool do Grupo Balbo - Sertãozinho e Jardinópolis. 
nais foram ignoradas ou desprezadas pelas camadas mais eruditas da população. Segundo FERRARI ${ }^{6}$, eram consideradas como prática anticientífica, atividade de curandeiros ou tão ineficazes quanto água com açúcar.

As plantas medicinais vêm sendo usadas há séculos e, nos últimos anos, elas reaparecem com força revigorada, num momento de retorno à natureza que eclodiu em muitos países nas últimas décadas, como reação aos exageros e abusos no emprego de produtos químicos e substâncias sintéticas (FERRARI) ${ }^{6}$.

É fácil constatar que, ultimamente, a discussão e o interesse sobre plantas que poderiam ter efeitos terapêuticos ganharam novo ímpeto, àdquirindo status de moda. Surgem também de maneira velada críticas, principalmente de instituições oficiais de amparo à pesquisa, segundo afirma CAR. $\mathrm{LINl}^{3}$ "de que as pesquisas até agora financiadas não trouxeram resultado prático, isto é, nenhum remédio foi desenvolvido. No entanto nos países desenvolvidos, uma droga nova até transformar-se em medicamento demora de $5 \cdot 10$ anos e custa várias dezenas de milhões de dólares."

Desde os primórdios da humanidade, o uso de plantas medicinais esteve bastan te ligado à religião.

No Brasil, identificam-se na formação de nossa medicina popular, três influências prevalentes quais sejam: a do colonizador português, cuja Corte Real reteve, o que é lógico, os melhores médicos, enviando um contingente pouco confiável à colônia; a dos índios, os nativos do território, que utilizavam a fitoterapia dentro de uma visão mística e por vezes mágica, onde o pajé ou feiticeiro da tribo utilizava plantas entorpecentes para sonhar com o espírito que lhe revelava então a erva, ou o procedimento a ser seguido para a cura do enfermo; e a dos negros, principalmente malés, africanos trazidos como escravos e com uma medicina mágica, caracterizando-se pela prática da expulsão de demônio e por um uso maior de substâncias animais, em relação ao índio (MATOS) ${ }^{8}$.

No século XVIII, surge a homeopatia com o médico Samuel Christian Hahnemann que, fazendo experiência consigo mesmo tomando quinino e provocando em seu organismo todos os sintomas semelhantes à malária, identificou a importância de sua observação e formulou o princípio da similia, similibus curantur (o semelhante se cura pelo semelhante) que publicou em 1796 criando a homeopatia. Hahnemann veio renovar a tradição duas vezes milenar de Hipócrates que escre- vera, três séculos antes de Cristo: "A doença é produzida pelos semelliantes e, pelos semelhantes que são ministrados, o paciente volta da doença à saúde" (TERAPIAS alternativas) ${ }^{14}$.

A partir daí, inicia-se a experimentaçãu com muitos produtos vegetais, animais e minerais, em homem são, e pelos efeitos indicavam-se as substâncias para aquelas doenças que apresentassem aqueles efeitos.

Em 1800, Hahnemann lança a doutrina da dinamização ou seja, que os medicamentos homeopáticos são mais ativos à medida que vão sendo diluídos. Ainda hoje a homeopatia se baseia nos princípios estabelecidos por Hahnemann (CAR. LINI) ${ }^{4}$.

O Conselho Federal de Medicina do Brasil, após reconhecer em 1980 a homeopatia como especialidade médica, determina que só pode se anunciar especialista em honieopatia aquele que tenha feito jus ao diploma de especialista em homeopatia, emitido pelo próprio Conselho (DANTAS) ${ }^{5}$.

Usando a terminologia usual: "medicina oficial" (alopática) e para as demais restantes "alternativas", o que existe, na verdade, são formas da população resolver seus problemas de saúde.

À medıda que o sistema de assistência médica exclui uma parcela da população, uma forma de buscar alternativas para falhas neste sistema de saúde é o indivíduo procurar outras fontes que não a medicina oficial.

Por reconhecer a necessidade da área da saúde identificar a legitimação dessas práticas na comunidade, é que este trabalho foi realizado; para que, com ele, surjam discussões e propostas, principalmente considerando a importância deste assunto ser levado às Escolas onde se formam os recursos para a área da saúde.

\section{OBJETIVO}

Conhecer a maneira pela qual a fitoterapia e a homeopatia são utilizadas como práticas médicas pela comunidade.

Espera-se que os resultados venham contribuir para que o enfermeiro conheça como as pessoas se utilizam de recursos, que não os da medicina oficial, para a solução de seus problemas de saúde, e como elas aderiram a essas práticas. 
METODOLOGIA E POPULAÇÃO

Fez-se uma entrevista através de um questionário (ANEXO 1) onde se anotavam as informaçð̄es.

$\mathrm{O}$ questionário foi pré-testado num serviço de saúde que não fazia parte do trabalho. Fizeram-se as correções e elaborou-se um novo modelo. Os aplicadores na fase de teste e na fase efetiva do trabalho foram duas enfermeiras de saúde pública.

Toda pessoa era antes convidada à entrevista e, desde que a aceitasse, a misma era efetivada. Não havia nenhum critério de seleção para isto, apenas o da pessoa estar naquele local e se predis. por a ser entrevistada.

A população constou de mulheres sendo: alunas do curso de habilitação de enfermagem de saúde pública, da EERP-USP, pacientes do ambulatório do INAMPS (ambulatório geral) e mães que freqüentam a pediatria do Centro de Saúde I, da Secretaria de Estado da Saúde de São Paulo, todas da cidade de Ribeirão Preto. Foram feitas trinta entrevistas em citda grupo, totalizando noventa pessoas entrevistadas.

\section{RESULTADOS}

Tabela 1 - Distribuição dos entrevistados segundo Grupo Etário e local onde foi entrevistado

\begin{tabular}{l|c|c|c|cc}
\hline \multicolumn{1}{c|}{ Idade em } & Centro de & Alunos & \multicolumn{2}{|c}{ Total } \\
Anos & Saúde & INAMPS & EE & No & $\%$ \\
\hline $20-30$ & 18 & 06 & 28 & 52 & 57,7 \\
$301-40$ & 10 & 09 & 01 & 20 & 22,2 \\
$40-50$ & 01 & 09 & 01 & 11 & 12,2 \\
$50 \vdash-60$ & 01 & 02 & - & 03 & 3,3 \\
60 e mais & - & 30 & 30 & 90 & 4,4 \\
\hline Total Geral & 30 & & & & 100 \\
\hline
\end{tabular}

Tabela 2 Distribuição dos entrevistados segundo seu grau de escolaridade e o local da ẹntrevista

\begin{tabular}{|c|c|c|c|c|c|}
\hline \multirow{2}{*}{$\begin{array}{l}\text { Grau de } \\
\text { Instrução }\end{array}$} & \multirow{2}{*}{$\begin{array}{l}\text { Centro de } \\
\text { Saúde }\end{array}$} & \multirow{2}{*}{ INAMPS } & \multirow{2}{*}{ Alunos } & \multicolumn{2}{|c|}{ Total } \\
\hline & & & & Nọ & $\%$ \\
\hline Analfabeto & 04 & 02 & - & 06 & 6,7 \\
\hline Primeiro Grau & & & & & \\
\hline incompleto & 21 & 25 & - & 46 & 52,0 \\
\hline $\begin{array}{l}\text { completo } \\
\text { compling }\end{array}$ & 03 & 01 & - & 04 & 4.4 \\
\hline Segundo Grau & ( & & & & \\
\hline $\begin{array}{l}\text { incompleto } \\
\text { Segundo Grau }\end{array}$ & 02 & 01 & - & 03 & 3,3 \\
\hline completo & - & 01 & - & 01 & 1,1 \\
\hline $\begin{array}{l}\text { Superior (cur- } \\
\text { sando) }\end{array}$ & - & - & 30 & 30 & 33,3 \\
\hline Total Geral Nọ & 30 & 30 & 30 & 90 & 100 \\
\hline
\end{tabular}


Tabela 3 - Distribuição dos entrevistados segundo sua ocupação/profissão e o local onde foi entrevistado

\begin{tabular}{l|c|c|c|cc}
\hline \multicolumn{1}{c|}{ Ocupação e/ou } & Centro de & & \multicolumn{2}{c}{ Total } \\
\multicolumn{1}{c|}{ Profissão } & Saúde & INAMPS & Alunos & No & $\%$ \\
\hline Do lar & 21 & 20 & - & 41 & 45,5 \\
Estudante & - & - & 30 & 30 & 33,3 \\
Emp. Doméstica & 07 & 03 & - & 10 & 11,1 \\
Aposentado & - & 02 & - & 02 & 2,22 \\
Comerciante & 01 & - & - & 01 & 1,11 \\
Cabeleireira & 01 & 01 & - & 01 & 1,11 \\
Desempregada & - & 01 & - & 01 & 1,11 \\
Faz salgados & - & 01 & - & 01 & 1,11 \\
Esteticista & - & 01 & - & 01 & 1,11 \\
Func. Público & - & 30 & 30 & 90 & 1,11 \\
Atend. Enf. & - & & & \\
\hline \multicolumn{1}{c|}{ Total No } & 30 & & & & 01 \\
\hline
\end{tabular}

Tabela 4 - Distribuição das pessoas entrevistadas segundo o hábito de tomar chá e o local em que foram entrevistados

\begin{tabular}{c|c|c|c|cc}
\hline \multirow{2}{*}{$\begin{array}{c}\text { Uso de chá } \\
\text { habitualmente }\end{array}$} & Locais & INAMPS & Alunos & \multicolumn{2}{|c}{ Total } \\
\hline Sim & 02 & & & No & $\%$ \\
& $6,6 \%$ & $53,3 \%$ & $80 \%$ & 42 & 46,7 \\
Não & 28 & 14 & 06 & 48 & 53,3 \\
& $93,3 \%$ & $46,6 \%$ & $20 \%$ & & \\
\hline Total No & 30 & 30 & 30 & 90 & 100 \\
$\%$ & $31,1 \%$ & $31,1 \%$ & $31,1 \%$ & 90 & 100 \\
\hline
\end{tabular}


Tabela 5 - Distribuição das pessoas entrevistadas segundo o uso que fazem de plantas como medicamento, suas justificativas de acordo com o local da entrevista

\begin{tabular}{|c|c|c|c|}
\hline \multirow{2}{*}{$\begin{array}{l}\text { Local da } \\
\text { entrevista }\end{array}$} & \multicolumn{2}{|c|}{$\begin{array}{l}\text { Utiliza } \\
\text { planta }\end{array}$} & \multirow[t]{2}{*}{ Justificativa } \\
\hline & Sim & Não & \\
\hline \multirow{5}{*}{$\begin{array}{l}\text { Centro de } \\
\text { Saúde }\end{array}$} & $\begin{array}{l}07 \\
08\end{array}$ & $\begin{array}{l}- \\
-\end{array}$ & \multirow{22}{*}{$\begin{array}{l}\text { Natural; não faz mal; mais barato; muito bom; não tem químicas. } \\
\text { Melhor que remédio; mais fácil que remédio; costume usá-las; dis- } \\
\text { pensa médico; complementa remédio. } \\
\text { Foi orientação médica; pode resolver o problema sem médico; ali- } \\
\text { via bastante e tira a dor. } \\
\text { Mãe ensinou que planta é bom; veio da roça e não comprava re- } \\
\text { médio. } \\
\text { Sem justificativa. } \\
\text { Não gosta; não acredita; não resolve mais; não sabe e nunca usou. } \\
\text { Sem justificativa. }\end{array}$} \\
\hline & 05 & - & \\
\hline & 02 & $\cdots$ & \\
\hline & 02 & - & \\
\hline & $\begin{array}{l}- \\
-\end{array}$ & $\begin{array}{l}04 \\
02\end{array}$ & \\
\hline Semitotal & 24 & 06 & \\
\hline$\%$ & 80 & 20 & \\
\hline & 17 & - & \\
\hline & 05 & - & \\
\hline INAMPS & 03 & - & \\
\hline & - & 02 & \\
\hline & - & 03 & \\
\hline Semitotal & 25 & 05 & \\
\hline$\%$ & 83,3 & 16,6 & \\
\hline \multirow{4}{*}{ alunos } & 06 & - & \\
\hline & 05 & - & \\
\hline & 18 & - & \\
\hline & - & 01 & \\
\hline Semitotal & 29 & 01 & \\
\hline$\%$ & 96,6 & 0,3 & \\
\hline Total & 78 & 12 & \\
\hline$\%$ & 86,6 & 13,3 & \\
\hline
\end{tabular}


Tabela 6 - Distribuição dos 78 entrevistados que usam plantas segundo indicação feita de como aprendeu a usá-las e o local onde foi entrevistado

\begin{tabular}{|c|c|c|c|c|c|c|}
\hline $\begin{array}{c}\text { Como } \\
\text { aprendeu }\end{array}$ & $\begin{array}{l}\text { Local de } \\
\text { entrevista } \\
\mathrm{CS}_{1}\end{array}$ & INAMPS & Alunos & Total & $\%$ & \\
\hline $\begin{array}{l}\text { Mãe } \\
\text { Mãe e familiares } \\
\text { Mãe, médico, } \\
\text { vizinhos } \\
\text { Família e amigos } \\
\text { Amigas } \\
\text { Médico } \\
\text { Vizinhos e amigas } \\
\text { Avó e pessoas } \\
\text { idosas } \\
\text { Benzedeira } \\
\text { Sozinha } \\
\text { Revistas e TV } \\
\text { Avó e namorado }\end{array}$ & $\begin{array}{l}14 \\
05 \\
02 \\
\overline{01} \\
01 \\
- \\
- \\
- \\
01 \\
- \\
-\end{array}$ & $\begin{array}{l}14 \\
03 \\
01 \\
02 \\
01 \\
- \\
02 \\
01 \\
01 \\
- \\
- \\
-\end{array}$ & $\begin{array}{l}03 \\
16 \\
02 \\
02 \\
- \\
- \\
01 \\
03 \\
- \\
- \\
01 \\
01\end{array}$ & $\begin{array}{l}31 \\
24 \\
05 \\
04 \\
02 \\
01 \\
03 \\
04 \\
01 \\
01 \\
01 \\
01\end{array}$ & $\begin{array}{r}39,7 \\
30,7 \\
6,4 \\
5,1 \\
2,5 \\
1,2 \\
3,8 \\
\\
5,1 \\
1,2 \\
1,2 \\
1,2 \\
1,2\end{array}$ & 17,4 \\
\hline Total & 24 & 25 & 29 & 78 & 100 & \\
\hline
\end{tabular}

Tabela 7 - Distribuição dos 78 entrevistados que usam plantas segundo o tipo das mesmas ou frutos de acordo com o modo de usar e o local da entrevista

\begin{tabular}{|c|c|c|c|c|c|c|c|c|c|}
\hline \multirow{2}{*}{$\begin{array}{l}\text { No de } \\
\text { ordem }\end{array}$} & \multirow{2}{*}{$\begin{array}{c}\text { Nome da planta } \\
\text { ou fruto }\end{array}$} & \multicolumn{2}{|c|}{$\begin{array}{l}\text { Centro de } \\
\text { Saúde } 1\end{array}$} & \multicolumn{2}{|c|}{ INAMPS } & \multicolumn{2}{|c|}{ Alunos E.E. } & \multicolumn{2}{|c|}{ Total } \\
\hline & & Chá & $\begin{array}{l}\text { Outras } \\
\text { Formas }\end{array}$ & Chá & $\begin{array}{l}\text { Outras } \\
\text { Formas }\end{array}$ & Chá & $\begin{array}{l}\text { Outras } \\
\text { Formas }\end{array}$ & Chá & $\begin{array}{l}\text { Outras } \\
\text { Formas }\end{array}$ \\
\hline 01 & Hortelã & 15 & 01 & 16 & - & 16 & 03 & 47 & 04 \\
\hline 02 & Erva-Cidreira & 07 & - & 13 & - & 27 & 01 & 47 & 01 \\
\hline 03 & Boldo & - & 04 & 05 & 03 & 09 & 07 & 28 & 14 \\
\hline 04 & Erva-Doce & 03 & m & 03 & $\ldots$ & 20 & - & 26 & $\ldots$ \\
\hline 05 & Poejo & 09 & & 08 & - & 01 & & 18 & $\ldots$ \\
\hline 06 & Limão & 02 & 01 & 01 & 01 & 05 & 06 & 16 & 08 \\
\hline 07 & Confrei & 01 & 01 & 02 & - & 06 & 04 & 14 & 05 \\
\hline 08 & Marcela & 06 & 01 & 02 & - & 01 & 03 & 13 & 04 \\
\hline 09 & Camomila & 01 & - & - & - & 10 & - & 11 & - \\
\hline 10 & Quebrapedra & 03 & - & 01 & - & 06 & 01 & 11 & 01 \\
\hline 11 & Canela & - & - & 01 & - & 09 & - & 10 & - \\
\hline 12 & Alho & - & - & - & - & 05 & 09 & 09 & 09 \\
\hline 13 & Mate & - & - & - & - & 09 & - & 09 & - \\
\hline 14 & Eucalipto & 01 & - & - & 01 & 01 & 06 & 09 & 07 \\
\hline 15 & Guaraná & - & - & - & - & - & 06 & 06 & 06 \\
\hline 16 & Babosa & -- & - & - & 01. & - & 04 & 05 & 05 \\
\hline 17 & Picão & - & - & 01 & 02 & - & 02 & 05 & 04 \\
\hline 18 & Maracujá & - & - & - & - & - & 05 & 05 & 05 \\
\hline 19 & Losna & - & 03 & 01 & - & - & - & 04 & - \\
\hline 20 & Agriāo & - & 01 & - & - & 01 & 02 & 04 & 03 \\
\hline 21 & Elevante & 03 & - & 01 & - & - & - & 04 & - \\
\hline 22 & Follha goiabeira & - & - & - & - & - & 03 & 03 & 03 \\
\hline
\end{tabular}




\begin{tabular}{|c|c|c|c|c|c|c|c|c|c|}
\hline \multirow{2}{*}{$\begin{array}{l}\text { Nọ de } \\
\text { ordem }\end{array}$} & \multirow{2}{*}{$\begin{array}{c}\text { Nome da planta } \\
\text { ou fruto }\end{array}$} & \multicolumn{2}{|c|}{$\begin{array}{c}\text { Centro de } \\
\text { Saúde } 1\end{array}$} & \multicolumn{2}{|c|}{ INAMPS } & \multicolumn{2}{|c|}{ Alunos E.E. } & \multicolumn{2}{|c|}{ Total } \\
\hline & & Chá & $\begin{array}{l}\text { Outras } \\
\text { Formas }\end{array}$ & Chá & $\begin{array}{l}\text { Outras } \\
\text { Formas }\end{array}$ & Chá & $\begin{array}{l}\text { Outras } \\
\text { Formas }\end{array}$ & Chá & $\begin{array}{l}\text { Outras } \\
\text { Formas }\end{array}$ \\
\hline 23 & Follua abacate & 01 & & $m$ & - & - & 02 & 03 & 02 \\
\hline 24 & Sabugueiro & 01 & 02 & & & $\ldots$ & & 03 & 02 \\
\hline 25 & Alecrim & 01 & - & 01 & - & 01 & - & 03 & - \\
\hline 26 & Rosa Branca & 01 & - & - & - & - & 02 & 03 & 02 \\
\hline 27 & Mentrasto & - & - & 02 & - & - & - & 02 & - \\
\hline 28 & Funcho & - & - & 02 & - & - & - & 02 & - \\
\hline 29 & Xuxu & - & -. & 02 & _- & $\therefore$ & & 02 & - \\
\hline 30 & Alfavaca & - & - & 01 & 01 & - & - & 01 & 01 \\
\hline 31 & Alface & - & - & - & - & - & 02 & - & 02 \\
\hline 32 & Arnica & - & - & - & - & - & 02 & - & 02 \\
\hline 33 & Melissa & 02 & - & - & - & - & - & 02 & - \\
\hline 34 & Folha mamoeiro & - & - & - & - & 01 & 01 & 02 & 01 \\
\hline 35 & Cânfora & - & 01 & - & - & - & 01 & - & 02 \\
\hline 36 & Noz-moscada & 01 & - & - & - & - & - & 01 & - \\
\hline 37 & Flor de mamão & - & 01 & - & - & - & - & - & 01 \\
\hline 38 & Erva-S. João & - & 01 & - & - & - & - & - & 01 \\
\hline 39 & Panacéia & 01 & - & & - & - & - & 01 & - \\
\hline 40 & Còco Macaúva & 01 & & -. & - & - & - & 01 & \\
\hline 41 & Banana de & & & & & & & & \\
\hline & macaco & 01 & - & - & - & - & -. & 01 & - \\
\hline 42 & Cabelo de milho & 01 & - & - & - & - & - & 01 & - \\
\hline 43 & Algodão & 01 & - & - & - & - & - & 01 & - \\
\hline 44 & Coentro & 01 & - & - & - & - & - & 01 & - \\
\hline 45 & Manjerona & 01 & - & - & - & - & - & 01 & \\
\hline 46 & Mamica de cadela & & - & - & 01 & - & - & - & 01 \\
\hline 47 & Algodãozinho & - & - & - & 01 & - & - & - & 01 \\
\hline 48 & Carolinha & - & - & - & 01 & - & - & - & 01 \\
\hline 49 & Alho & - & - & - & 01 & - & - & - & 01 \\
\hline 50 & Cipó São Cuctano & - & - & - & 01 & - & - & - & 01 \\
\hline 51 & Romã & - & - & 01 & - & - & - & 01 & - \\
\hline 52 & Chapéu cravo & - & - & 01 & - & - & - & 01 & - \\
\hline 53 & Rama Mandioca & - & - & - & 01 & - & - & - & 01 \\
\hline 54 & Erva-terrestre & - & - & 01 & - & - & - & 01 & - \\
\hline 55 & Erva-Sta. Maria & - & - & - & 01 & - & - & - & 01 \\
\hline 56 & Artemísia & - & - & 01 & - & - & - & 01 & - \\
\hline 57 & Fedegoso & - & - & 01 & - & - & - & 01 & - \\
\hline 58 & Malva Branca & - & - & 01 & - & - & - & 01 & - \\
\hline 59 & Conta de lágrimas & - & - & - & - & 01 & - & 01 & - \\
\hline 60 & Urucum & - & - & - & - & - & 01 & - & 01 \\
\hline 61 & Arruda & - & - & - & - & - & 01 & - & 01 \\
\hline 62 & Mulatinha & - & - & - & - & - & 01 & - & 01 \\
\hline 63 & Fava Sucupira & - & - & - & - & - & 01 & - & 01 \\
\hline 64 & Mentrasto & - & - & - & - & 01 & - & 01 & - \\
\hline 65 & Rabanete & - & - & - & - & 01 & - & 01 & - \\
\hline 66 & Gengibre & - & - & - & - & - & 01 & - & 01 \\
\hline 67 & Carqueja & - & - & - & - & 01 & - & 01 & - \\
\hline 68 & Folha mamona & - & - & - & - & - & 01 & - & 01 \\
\hline 69 & Beladona & - & - & - & - & - & 01 & - & 01 \\
\hline & Total & 65 & 17 & 69 & 16 & 132 & 79 & 346 & 109 \\
\hline
\end{tabular}


Tabela 8 - Distribuição dos 78 entrevistados que usam plantas segundo indicação de onde obtêm as mesmas segundo o local da entrevista.

\begin{tabular}{l|c|c|c|c|c}
\hline \multicolumn{1}{r|}{$\begin{array}{c}\text { Local } \\
\text { entrevista }\end{array}$} & $\mathrm{CS}_{1}$ & INAMPS & Alunos & Total & $\%$ \\
Local & & & & & \\
onde obtém & 15 & 12 & 01 & 28 & 35,8 \\
\hline Próprio quintal & 04 & 05 & 10 & 19 & 24,3 \\
Próprio quin tal, vizinhos & 01 & 02 & 07 & 10 & 12,8 \\
e parentes & 01 & 01 & 05 & 07 & 8,9 \\
Farmácia e Supermercado & 02 & - & 05 & 07 & 8,9 \\
Amigus e parentes & 01 & 03 & 01 & 05 & 6,4 \\
Familiares & - & 01 & - & 01 & 1,2 \\
Vizinhos e parentes & - & 01 & - & 01 & 1,2 \\
Hortas & 24 & 25 & 29 & 78 & 100 \\
Mato & \multicolumn{1}{c|}{ Total } & & & \\
\hline
\end{tabular}


TABELA 9 - Distribuição dos entrevistados segundo a resposta se quer aprender a usar plantas e a justificativa segundo o local da en trevista

\begin{tabular}{|c|c|c|c|}
\hline \multirow{2}{*}{$\begin{array}{l}\text { Local da } \\
\text { Entrevista }\end{array}$} & \multicolumn{2}{|c|}{ Quer aprender } & \multirow{2}{*}{ Justificativa } \\
\hline & Sim & Não & \\
\hline $\begin{array}{l}\text { Centro } \\
\text { de } \\
\text { Saúde }\end{array}$ & $\begin{array}{l}10 \\
05 \\
04 \\
03 \\
02 \\
02 \\
03 \\
-\end{array}$ & $\begin{array}{l}- \\
- \\
- \\
- \\
- \\
- \\
01\end{array}$ & $\begin{array}{l}\text { Para aprender para que servem as plantas } \\
\text { É mais natural } \\
\text { É bom usar plantas } \\
\text { Remédio caseiro é melhor } \\
\text { Não tem contra-indicação } \\
\text { Para usar melhor } \\
\text { É mais barato, evita comprar remédio, não ir ao médico } \\
\text { Acha difícil preparar os remédios com plantas }\end{array}$ \\
\hline $\begin{array}{c}\text { Subtotal } \\
\%\end{array}$ & $\begin{array}{c}29 \\
96,6\end{array}$ & $\begin{array}{l}01 \\
3,3\end{array}$ & \\
\hline INAMPS & $\begin{array}{l}09 \\
05 \\
03 \\
04 \\
02 \\
01 \\
- \\
- \\
- \\
- \\
-\end{array}$ & $\begin{array}{l}- \\
- \\
- \\
- \\
- \\
02 \\
01 \\
01 \\
01 \\
01\end{array}$ & $\begin{array}{l}\text { Para conhecer melhor as plantas } \\
\text { Melhor tratamento do que remédio de farmácia } \\
\text { Não tem contra-indicação } \\
\text { É mais barato e mais natural } \\
\text { Evita comprar e não precisa ir ao médico } \\
\text { Porque os remédios vêm das plantas } \\
\text { Não acredita em cura pelas plantas } \\
\text { Não gosta de mexer com plantas } \\
\text { Não se usa atualmente } \\
\text { Não tem paciência para preparar remédio } \\
\text { Acha que tem efeito lento }\end{array}$ \\
\hline Subtotal & 24 & 06 & \multirow{7}{*}{$\begin{array}{l}\text { É mais natural } \\
\text { Não tem contra-indicação } \\
\text { Para aprender melhor e poder usa } \\
\text { Acredita que as plantas curam } \\
\text { É mais barato } \\
\text { Para conhecimento geral } \\
\text { Sem justificativa }\end{array}$} \\
\hline$\%$ & 80 & 20 & \\
\hline Alunos & $\begin{array}{l}11 \\
07 \\
06 \\
02 \\
02 \\
01 \\
01\end{array}$ & $\begin{array}{l}- \\
- \\
- \\
- \\
- \\
-\end{array}$ & \\
\hline Subtotal & 30 & - & \\
\hline$\%$ & 100 & - & \\
\hline Total & 83 & 07 & \\
\hline Geral & 82,2 & 23,3 & \\
\hline
\end{tabular}


TABELA 10 - Distribuição das pessoas entrevistadas segundo seu conhecimento sobre a homeopatia, como ocorreu e segundo o local onde foi en trevistado

\begin{tabular}{|c|c|c|c|}
\hline \multirow{2}{*}{$\begin{array}{l}\text { Local da } \\
\text { Entrevista }\end{array}$} & \multicolumn{2}{|c|}{ Se já ouviu falar } & \multirow{2}{*}{ Onde ouviu falar } \\
\hline & Sim & Não & \\
\hline $\begin{array}{c}\text { Centro de } \\
\text { Saúde I }\end{array}$ & $\begin{array}{l}15 \\
02 \\
01 \\
01\end{array}$ & $\begin{array}{l}- \\
- \\
- \\
\overline{11}\end{array}$ & \multirow{11}{*}{$\begin{array}{l}\text { Não se lembra } \\
\text { Com parentes e amigos } \\
\text { Livros } \\
\text { Amigos } \\
\text { Não se lembra } \\
\text { Amigos } \\
\text { Parentes e familiares que se tratam com homeopatia } \\
\text { Vizinhos que se tratam com homeopatia } \\
\text { Emn instituições } \\
\text { Com vendedores } \\
\text { Propaganda dos meios de comunicação } \\
\text { Farmácias } \\
\text { - }\end{array}$} \\
\hline Subtotal & 19 & -11 & \\
\hline$\%$ & 63,3 & 36,6 & \\
\hline INAMPS & $\begin{array}{c}06 \\
12 \\
03 \\
02 \\
01 \\
01 \\
01 \\
01 \\
-\end{array}$ & $\begin{array}{l}- \\
- \\
- \\
- \\
- \\
- \\
- \\
- \\
03\end{array}$ & \\
\hline Subtotal & 27 & 03 & \\
\hline$\%$ & 90 & 10 & \\
\hline Alunos & $\begin{array}{l}04 \\
05 \\
05 \\
05 \\
07 \\
03 \\
01\end{array}$ & $\begin{array}{l}- \\
- \\
- \\
- \\
- \\
- \\
-\end{array}$ & \\
\hline Subtotal & 30 & - & \\
\hline$\%$ & 100 & - & \\
\hline Total Geral & 76 & 14 & \\
\hline$\%$ & 84,4 & 15,5 & \\
\hline
\end{tabular}


TABELA 11 - Distribuição das pessoas entrevistadas segundo as respostas: se já usaram homeopatia e se desejam conhecê-la segundo o local em que foram entrevistadas

\begin{tabular}{|c|c|c|c|c|c|c|c|c|}
\hline \multirow{2}{*}{\multicolumn{2}{|c|}{$\begin{array}{l}\text { Local da } \\
\text { Entrevista }\end{array}$}} & \multicolumn{2}{|c|}{$\begin{array}{c}\text { Já usou } \\
\text { homeopatia }\end{array}$} & \multicolumn{3}{|c|}{ Quem indicou } & \multicolumn{2}{|c|}{$\begin{array}{l}\text { Gostaria de } \\
\text { aprender }\end{array}$} \\
\hline & & Sim & Não & Médico & $\begin{array}{l}\text { Parentes } \\
\text { amigos }\end{array}$ & Farmac. & Sim & Não \\
\hline $\begin{array}{l}\mathrm{CS}_{1} \\
\text { INAM } \\
\text { Aluno }\end{array}$ & & $\begin{array}{l}04 \\
09 \\
13\end{array}$ & $\begin{array}{l}26 \\
21 \\
17\end{array}$ & $\begin{array}{l}01 \\
01 \\
03\end{array}$ & $\begin{array}{l}03 \\
05 \\
07\end{array}$ & $\begin{array}{l}-\overline{03} \\
03\end{array}$ & $\begin{array}{l}27 \\
27 \\
29\end{array}$ & $\begin{array}{l}03 \\
03 \\
01\end{array}$ \\
\hline \multirow{2}{*}{ Total } & Nọ & 26 & 64 & 05 & 15 & 06 & 83 & 07 \\
\hline & $\%$ & 28,8 & 71,1 & 5,5 & 16,6 & 6,6 & 92,2 & 7,7 \\
\hline
\end{tabular}


TABELA 12 - Distribuição das pessoas entrevistadas segundo sua resposta se gostariam de fazer tratamento com médico homeopático segundo o local de entrevista

\begin{tabular}{|c|c|c|c|}
\hline \multirow{2}{*}{$\begin{array}{l}\text { Local da } \\
\text { Entrevista }\end{array}$} & \multicolumn{2}{|c|}{$\begin{array}{l}\text { Gostaria de tratrar } \\
\text { com homeopata }\end{array}$} & \multirow[t]{2}{*}{ Justificativa } \\
\hline & Sim & Não & \\
\hline $\begin{array}{l}\text { Centro } \\
\text { de } \\
\text { Saúde I }\end{array}$ & $\begin{array}{l}09 \\
05 \\
04 \\
01 \\
07 \\
- \\
-\end{array}$ & $\begin{array}{l}- \\
- \\
- \\
- \\
- \\
03 \\
01\end{array}$ & \multirow{11}{*}{$\begin{array}{l}\text { Bom tratamento e é natural } \\
\text { Para conhecer o tratamento } \\
\text { Por estar cansado de outros tratamentos } \\
\text { Tem doente na famılia } \\
\text { É melhor que farmácia } \\
\text { Não conhece a respeito } \\
\text { Não é bom e não acredita } \\
\text { Já fez e não deu certo } \\
\text { Sem justificativa }\end{array}$} \\
\hline Subtotal & 26 & 04 & \\
\hline$\%$ & 86,6 & 13,3 & \\
\hline INAMPS & $\begin{array}{l}13 \\
06 \\
01 \\
01 \\
01 \\
- \\
- \\
- \\
-\end{array}$ & $\begin{array}{l}- \\
- \\
- \\
- \\
- \\
03 \\
02 \\
01 \\
02\end{array}$ & \\
\hline Subtotal & 22 & 08 & \\
\hline$\%$ & 73,3 & 26,6 & \\
\hline Alunos & $\begin{array}{l}13 \\
03 \\
02 \\
05 \\
- \\
- \\
-\end{array}$ & $\begin{array}{l}- \\
- \\
- \\
\overline{0} \\
03 \\
02 \\
02\end{array}$ & \\
\hline Subtotal & 23 & 07 & \\
\hline$\%$ & 76,6 & 23,3 & \\
\hline \multirow{2}{*}{ Total Geral } & 71 & 19 & \\
\hline & 78,8 & 21,1 & \\
\hline
\end{tabular}




\section{DISCUSSÃO}

Segundo os dados apresentados nas tabelas 1, 2 e 3 , a população entrevistada caracterizou-se segundo o grupo etário numa população jovem com $57,7 \%$ na faixa de $20 / 30$ anos e $22,2 \%$ entre 30 e 40 anos, diminuindo sensivelmente até os 60 e mais. Isto se deve, em parte, pelo fato de se ter incluído na amostra alunos de graduação em enfermagem e que as mulheres estão se tornando mães ainda jovens.

A escolaridade dessa população em 52\% (a maior porcentagem) ficou para os que têm o primeiro grau incompleto, seguido de $33,3 \%$ que foram os universitários incluídos.

A ocupação de maior freqüência foi a ligada ao lar, $45,5 \%$, o que era de se esperar, uma vez que se trabalhou com população de Centro de Saúde e INAMPS.

Esta diferença entre os três grupos, colocando CS - Centro de Saúde, INAMPS e Universitários, teve como propósito evidenciar se o nível de escolaridade das pessoas influía no uso dessas terapias, ou não, o que se discutirá nas tabelas seguintes.

A Tabela 4 mostra a utilização do chá nessa população como hábito (não como medicação). Dos $46,7 \%$ que habitualmente utilizam, a maior freqüência ficou para os alunos universitários, com $80 \%$. Há evidência de que os mais simples, os do $\mathrm{CS}_{1}(6,6 \%)$ são os que menos utilizam, sendo seguidos pelos do INAMPS com $53,3 \%$.

Isto deixa claro que, nessa população estudada, o chá não é hábito comum como refeiçōes, ou como substituição do café, pois menos da metade da população o utiliza e o faz segundo o nível a que pertençam. Estes dados podem justificar o raciocínio de que os que já utilizam habitualmente chás terão mais facilidade de incorporar o hábito de utilizar chás de ervas medicinais, do que os que nunca os utilizaram sob nenhuma forma.

A Tabela 5 mostra que, de todos os entrevistados, apenas $86,6 \%$ se utilizam de plantas como medicamento e que há diferença nessa utilização segundo o local em que recebem a assistência médica. Assim, $80 \%$ da do $\mathrm{CS}_{1}$, seguido de $83,3 \%$ do INAMPS e $96,6 \%$ das alunas da E. E. que são atendidas pelo serviço do Hospital das Clínicas de Ribeirão Preto, Serviço Médico do COSEAS (USP) e médicos particulares.

Quanto à justificativa, os três grupos lembram que é tratamento mais natural, mais fácil, melhor e de menor custo e sem efeito colateral.
Hoje há um cuidado a ser tomado, pois da postura do descrédito, tende-se a passar a um interesse incomum, chegando a um exagero quanto à ação medicinal de plantas e frutos.

$O$ ideal é alcançar aquele ponto que FERRA. $\mathrm{RI}^{6}$ afirma ser o espaço racional, quando são afastadas as concepçбes de inutilidade ou de milagre, e então as plantas passam a ser tratadas com a seriedade que merecem. Há todo um processo de amadurecimento no Brasil. Reflexo disso é a iniciativa da CEME de incentivar o estudo de plantas medicinais, principalmente as consideradas antitussígenas, antitérmicas e antidiabéticas, para um possível emprego na rede previdenciária.

Quando as pessoas indicam que as plantas "são naturais, sem produtos químicos e sem efeito colateral", é preciso lembrar que nenhuma delas deve ser usada indiscriminadamente, pois podem conter substâncias tóxicas prejudiciais à saú. de. $O$ seu uso deve ser moderado, de preferência seguindo orientação de quem conhece a planta para que se obtenha o efeito desejado, seguindo seus princípios ativos.

FERRARI ${ }^{6}$ lembra o perigo de se colherem plantas nos taludes das estradas ou as que crescem à beira de campos cultivados. Ambas podem estar contaminadas, as primeiras pelos gases emanados dos escapamentos de carros e as segundas, por salpicaduras de produtos químicos usados como adubos ou inseticida.

É conhecida em nosso país como planta tóxica a "saia branca", "trombeteira", "saia de noiva", beladona, que já causou muitos acidentes. A ingestão de chá feito com algumas destas flores ou folhas pode produzir marcante estado de alteração psíquica, sendo esta a razão principal de seu uso com finalidades mágicas ou hedonísticas e a sua intoxicação segundo CARLINI ${ }^{2}$ é conhecida há milênios e, no Brasil, há mais de século há descrições a respeito.

Quanto aos que não utilizam, a maior porcentagem foi de pessoas que vão ao $\mathrm{CS}_{1}$. Por outro lado, na entrevista o grupo do INAMPS se mostrou mais fechado e mais resistente a participar. De um modo geral foram poucos no total os que não utilizam plantas, $13,3 \%$, e as posições são de não gostar, não acreditar, não saber e nunca usou. Não houve a rejeição pelo motivo de ter tentado e não ter dado certo.

A tabela 6 mostra os que utilizam plantas, e com quem eles aprenderam o seu uso. Fica claro que a figura da mãe se evidencia com $39,7 \%$ de sua 
posição garantida como quem ensina os filhos, e novamente sua pessoa aparece junto a outros familiares com $30,7 \%$ e, em terceiro lugar, novamente ao lado de médicos e vizinhos. A função de "professor" da figura da mãe orientando seus.próprios filhos e aos filhos de seus filhos é perpetuada em nossa amostra. Tradicionalmente, a mãe sempre foi em nossa sociedade a primeira mestra, e aqui com maior freqüência entre os que freqüentam o INAMPS e $\mathrm{CS}_{1}$, pois é conhecido que nas doenças de netos os avós sempre são chamados para ajudar com sua experiência.

'Já é tradição conhecida que o uso de plantas para fins medicinais vem desde achados arqueológicos além de citações em documentos importantes como Bíblia e outros. Embora cientificamente duvidoso, em muitos casos o uso medicinal de plantas silvestres e cultivadas tem passado de geração a geração através dos séculos. Assim, inúmeras plantas são até hoje utilizadas para os mesmos males que no passado remoto (BRASIL. Ministério da Saúde) $)^{1}$.

A população estudada, apesar de pequenas variações entre os três grupos, evidenciou a mãe como a fonte do conhecimento no uso de ervas e plantas. O conhecimento científico não é lembrado nem mesmo pelos universitários.

Na Tabela 7, os grupos são distribuídos segundo as plantas que usam e o modo de prepará-las.

$\mathrm{O}$ que fica evidente e o que nos parece importante é que, dentre aqueles que utilizam plantas, uma mesma pessoa usa vários chás, portanto dificulta cálculos específicos, pois os números não se mantêm constantes.

Há alguns chás que são comuns aos três grupos como por exemplo hortelã, erva-cidreira, erva-doce, poejo, boldo, etc., mas há alguns que ficam exclusivos de um grupo, por exemplo a folha de abacate para o $\mathrm{CS}_{1}$, o picão para o INAMPS e o guaraná para os alunos.

O que chama a atenção é que o grupo de alunos mostrou ser o que usa a maior quantidade de chás e outras formas de utilização de ervas medicinais e, em segundo lugar, o grupo do INAMPS. Isto evidencia que os que têm acesso ao conhecimento têm mais chance de conhecer fitoterapia, o que não invalida que o mesmo aconteça às suas famílias, pois, segundo a tabela anterior, a mãe e os familiares seus constituem a principal fonte de informações sobre o uso de plantas medicinais.

Estes resultados coincidem com os da Tabela 4, que é o uso habitual de chá, mostrando que os alunos também são os que mais utilizam esta bebida como refeição.

No total, foram apontados $69^{\circ}$ tipos de vegetais sob forma de folhas, frutos e grãos, que são utilizados, sendo que as combinações de chás no total geral foram $346 \mathrm{e}$, para outras formas de uso, 109.

O chá foi o modo mais indicado para o uso de produtos medicinais da flora.

Os dados da tabela 8 mostram a forma de obtenção das plantas: $35,8 \%$ vêm do próprio quintal, que é a maior porcentagem enquanto que a compra é feita em apenas $12,8 \%$, em farmácias e supermercados.

$\mathrm{O}$ interesse e a procura crescentes de plantas medicinais acabaram gerando problemas na comercialização. A lei da oferta e da procura vem assumindo dimensões catastróficas nessa área e, por causa disso, a fraude, a venda enganosa, como se a planta fosse medicinal, além da comercialização de produto inadequadamente colhido, dissecado e manipulado. FERRARI ${ }^{6}$ diz que os resultados acabam sendo negativos para quem compra e assim, mais uma vez, se contribui para o descrédito de algo que pode se transformar em excelente alternativa terapêutica.

Um problema a ser pensado também é que o aumento da demanda pode levar à colheita predatória. SCARONE ${ }^{13}$ afirma que o extratismo e a falta do cultivo racional estão acabando com nossas plantas medicinais, como o caso do jaborandi e do ipê roxo, ameaçados de extinção por esse motivo; outro fator é a exportação indiscriminada.

$O$ interesse em aprender sobre o uso de plantas medicinais está na tabela 9. Mostrou ser de um grande interesse para o grupo - $92,2 \%$, principalmente dos alunos de graduação, $100 \%$.

Uma justificativa comum dos três grupos foi "aprender e conhecer melhor as plantas e para que servem".

O grupo do INAMPS foi o que mostrou menor interesse em aprender (80\%), enquanto $20 \%$ desacreditam, não gostam e acham que o efeito é lento.

Apesar da literatura disponível e o conhecimento de mitos relativos à questão de vegetais, capazes, por exemplo, de interferir com as funções do cérebro, conhecidas coletivamente como psiquismo ou mente, há as que ativam e as que retardam aquelas funções. RIZZINI ${ }^{12}$, falando no assunto, faz uma listagem de 65 espécies vegetais psicoativas observadas no Brasil e OLIVEIRA ${ }^{11}$, continuando, alista as plantas em alucinógenas, 
estimulantes e depressoras, compreendendo espécies tipicamente brasileiras e algumas outras cultivadas ou importadas, como maconha, o cafeeiro e a noz-moscada.

Para que a população tenha acesso a esse conhecimento é necessário um trabalho amplo, lembrando a necessidade da pesquisa, da disponibilidade de laboratório, do ensino para o pessoal que se prepara para atuar na área da saúde, depois a abordagem da comunidade por recursos de educação ém saúde estimulando e ensinando o uso de plantas, ensinando como colher, como preparar e como utilizar, estimulando a plantação e cultivo caseiro dessas ervas. Por outro lado, deve-se procurar obter da comunidade as informações sobre seu conhecimento de plantas medicinais, para o enriquecimento da experiência e do conhecimento do pessoal que atua nos serviços de saúde.

A nível das Escolas Superiores que formam pessoal da área da saúde, seria o de enfrentar o descrédito com que a medicina oficial encara a fitoterapia, mas isto pode ser vencido pelos pesquisadores básicos e clínicos de reconhecida capacidade científica e assim os médicos poderiam prescrever as plantas estudadas de reconhecido valor terapêutico (CARLINI) ${ }^{3}$.

O esclarecimento à população que, segundo a amostra do trabalho, é desejado, viria aclarar dúvidas evitando erros clássicos como o caso do diabete que, por não ter cura, tem sido tratada na medicina popular por inúmeras plantas consideradas antidiabéticas. SCARONE ${ }^{13}$ cita que seu levantamento conta com mais de 100 espécies de plantas hipoglicemiantes. Convém destacar que as plantas medicinais não substituem a insulina mas os medicamentos orais hipoglicemiantes permitem a redução da dosagem e um regime alimentar mais brando. Segundo esse autor, com relação às plantas medicinais, não foi isolado um componente de ação antidiabética, mas sim frações com propriedades, mais ou menos, hipoglicemiantes.

O conhecimento sobre a homeopatia é mostrado na tabela 10 , evidenciando que $84,4 \%$ da populaçao estudada a conhece, no entanto os que menos a conhecem são os do Centro de Saúde, seguidos do INAMPS. $100 \%$ dos alunos a conhecem. Os meios através dos quais tomaram conhecimento desta terapêutica, para os três grupos, são parentes, familiares e amigos. No grupo de alunos, os meios de comunicação e a propaganda foram também lembrados.

A medicina popular (não oficial) faz parte da cultura de um povo e segundo NOGUEIRA ${ }^{10}$ "é o produto da vida em grupo; é o destilado das experiências de passadas gerações, transmitido por meio de aprendizagem consciente e inconsciente, isto é, um padrão ou plano de vida que norteia a existência pessoal e em grupo".

No caso da homeopatia, embora com principios terapêuticos diferentes, também se utiliza de plantas, e talvez isto seja um elo para se entender essa passagem de conhecimento a nível familiar e tradicional.

É inegável que nos últimos anos tem havido um ressurgimento de interesse pela homeopatia e, segundo muitas opiniões, tal renascimento se deve principalmente aos vários malefícios que os medicamentos da terapêutica oficial vêm trazendo aos pacientes. Ou seja, novamente parece que, mais do que pelas próprias qualidades, a homeopatia volta à tona pelas más qualidades da assim chamada terapêutica alopática (CARLINI) ${ }^{4}$.

A utilização da terapêutica homeopática e o desejo de conhecê-la são mostrados na Tabela 11. A utilização dessa terapêutica por $28,8 \%$ de todo o grupo evidencia que a homeopatia não é a terapêutica eleita dessa população, principalmente pela do $\mathrm{CS}_{1}$; os universitários mostraram ser os que mais a utilizam. A indicação do uso não está na mão do profissional de saúde que apareceu com $5,5 \%$ mas, novamente confirmando a tabela anterior, os parentes e amigos, com 16,6\%. Apesar de ser praticamente desconhecida, $92,2 \%$ da população quer aprender a usá-la.

Para facilidade do entendimento, juntamos a essa discussão a tabela seguinte, $n$ ? 12 , onde as pessoas opinaram pelo tratamento homeopático com médico, obtendo afirmativamente o resultado de $78,8 \%$, o que evidencia que mesmo sendo desconhecida é uma terapêtica desejada. A justificativa se baseia nos argumentos de que ela "é mais natural, não agride o organismo e é melhor que remédio de farmácia."

A população hoje se vê à frente de um dilema, pois de um lado ouve críticas sobre homeopatia e, de outro, as alegações que os medicamentos alopáticos podem gerar tantas doenças quanto as que curam. Mas o ressurgir da popularidade da homeopatia nos dias de hoje coincide com toda uma "onda naturalista" possivelmente como resultado dos abusos da indústria moderna de alimentos e remédios, havendo o perigo de passar de um pólo para outro (CARLINI) ${ }^{4}$.

A importância do esclarecimento à população 
e a utilização do médico homeopata, aquele que se especializou dentro de seu próprio currículo como acontece na Escola de Medicina e Cirurgia do Rio de Janeiro e no Curso Médico da Universidade Federal de Uberlândia ou através de cursos de pós-graduação, vem evitar que as pessoas se utilizem de medicamentos que popularmente são chamados homeopáticos e não são (DANTAS) ${ }^{5}$. Há muitas distorçōes nesse sentido, pois há farmácias homeopáticas que vendem chás, vitaminas, complementos dietéticos e outros produtos, como cosméticos e de higiene, e muitos consumidores pensam que são produtos homeopáticos.

É preciso lembrar, como anota DANTAS ${ }^{5}$, que o medicamento homeopático é qualquer substância, submetida a um processo conjunto de diluição e dinamização capazes de provocar tanto o surgimento de sintomas físicos e psíquicos no homem sadio como o desaparecimento destes mesmos sintomas numa pessoa doente; que o médico homeopata especializado não prescreve apenas em função do diagnóstico clínico, mas considera cada paciente com seus sintomas específicos, com sua particular maneira de adoecer.

Por questão de espaço, eliminamos detalhes sobre a utilização da homeopatia mas um deles era sobre medicamentos "homeopáticos" que as pessoas diziam ter usado. Um exemplo é a "fórmula 46", que tem na sua composição fenolftaleína, isto não é homeopático, mas esses medicamentos são lançados no comércio por laboratórios homeopáticos. Estes fatos dificultam o caminhar da homeopatia como uma terapêutica aceita e apregoada como desprovida de efeitos tóxicos.

Com toda terapêutica, a homeopatia não é isenta de críticas, lembrando colocaçð̃es de DAN$\mathrm{TAS}^{5}$, de que a maior delas ele faz ao fato da dinamização ou potenciação ou diluição, quando esta atinge um ponto em que, numa certa diluição, não mais existe sequer uma molécula da substância original. Daí o paciente tomar apenas o veículo inerte, e então como explicar o efeito terapêutico? Outra colocação do mesmo autor é da corrente "Unicista" que há na homeopatia, que não aceita o progresso do conhecimento, rejeitando até as vacinaçðes.

A crítica sempre foi necessária à ciência, é graças a ela que progride e evolui. Apesar dessas observações feitas, a homeopatia é uma terapêutica que atravessou os séculos com várias formas de ataques e críticas, com milhoes de adeptos convictos de seus efeitos positivos e exercida por profissio- nais que demonstram honestidade no exercício de sua prática, isto quer dizer "que o fato homeopático existe pois está consagrado pelo tempo e pelo uso"'(DANTAS) 5 .

Parece que a busca de terapêuticas que fogem à oficial pode estar ligada a uma forma de buscar alternativas para falhas no sistema de saúde quanto à abrangência do atendimento que ele possa of erecer à população de modo geral, e que a divisão entre uma prática médica oficial e práticas alternativas usadas pela população parece existir somente nas instituições que exercem a chamada medicina oficial, pois para a população o que ela procura é resolver os seus problemas de saúde, em conseqüência da incapacidade do sistema de os resolver.

"Para as classes trabalhadoras, saúde é identificada como capacidade de trabalho, daí o esforço deles por manterem em funcionamento essa capacidade de trabalho". (MEDICINA popular) ${ }^{9}$.

A medicina popular ou alternativa entra aí provendo a necessidade da população que nem o Estado e nem a medicina privada suprem, e que vai sendo legitimada.

Quando se fala em medicina alternativa ou popular ou tradicional, já se faz uma discriminação de classes, isto é, haveria uma do povo e uma de outras classes sociais, talvez mais privilegiadas, mas o que se precisa entender é que não é a medicina em si que faz a discriminação, mas a sua forma de organização. Não se quer valorizar uma mais que outra, pois todas, tanto a alopática quanto as demais formas terapêuticas têm o seu valor, mas o que está sendo evidenciado é como a população se utiliza das terapêuticas que existem, deixando claro que não deve haver oposição entre o que é chamado de uso popular e o que é científico.

Ao nível do discurso, há anotaçðes lembradas por NOGUEIRA ${ }^{10}$ do grupo de trabalho formado em Genebra em 1976 com a finalidade de promover e desenvolver a medicina tradicional e entre os objetivos preparados pelo grupo, está este: "promover a integração dos conhecimentos e técnicas de utilidade comprovada existentes na medicina científica e na medicina popular ou tradicional". Este mesmo autor lembra a recomendação da OMS feita em 1977 sobre a necessidade de investigações dos sistemas de medicina tradicional, principalmente trabalhos orientados para identificação de remédios eficazes, de origem vegetal, mineral e animal..., com a finalidade de reduzir o custo das importaçðes de medicamentos, nos países em desenvolvimento. 
FERRARI ${ }^{6}$ lembra que na verdade o que falta mesmo no Brasil é interesse da área oficial, amparo e estímulo à pesquisa. Enquanto isto não acontecer, dificilmente sairemos da situação de quase total desconhecimento de nossa flora medicinal. $\mathrm{O}$ que resta aos interessados é o estudo da literatura disponivel, pois tudo indica que vale a pena voltar-se para esta allternativa terapêutica: ela é simples, barata e acessivel a qualquer um.

\section{CONCLUSÃO}

A população estudada caracterizou-se como um grupo jovem - 57,7\% no grupo etário de 20 a 30 anos; com $52,0 \%$ com primeiro grau incompleto e $33,3 \%$ cursando o superior; com predominância de ocupação "do lar".

Apenas $46,7 \%$ se utilizam de chá como refeição e $86,6 \%$ utilizam chás de ervas medicinais e os que mais os utilizam são os universitários; a fonte do conhecimento dessa terapia foi a mãe, sozinha ou associada a familiares $-70,4 \%$; e a aquisição destas plantas é no próprio quintal $-35,8 \%$, ou associada à de vizinhos e parentes.

Dos 72 vegetais indicados, a maior combinação do uso foi dos universitários, com 132 indicações de chás e 72 outras para outros tipos de usos, seguidos pelo INAMPS e depois o $\mathrm{CS}_{1}$.

Da população, $92,2 \%$ querem aprender a utilizar plantas "para conhecer melhor, ser mais natural". Os que mostraram maior interesse foram os universitários, $100 \%$, seguidos dos do $\mathrm{CS}_{1}, 96,6 \%$ e por último os do INAMPS, $80 \%$.

Já ouviram falar da homeopatia $84,4 \%$ dos entrevistados, mas somente $28,8 \%$ já se utilizaram dela, por indicação principalmente de parentes e amigos - $16,6 \%$, mas $92,2 \%$ gostariam de aprender a utilizá-la por achá-la "natural, um bom tratamento e querer experimentar", na maioria dos que justificaram $(78,8 \%)$ querer tratar-se com médico homeopata.

Orientar a população para que esta conheça essas terapias alternativas, para que seu uso seja correto, e saiba combinar com elas os medicamentos alopáticos que ainda não possuem substitu tos.

O profissional da área da saúde deve estar atento para aprender a tirar da população a sua experiência, procurando entender essa realidade existente nessas terapias e que faz parte de sua cultura.

Os órgâios oficiais deverão estar atentos na comercialização e distribuição de plantas medicinais que ficam em poder de mãos que acabam levando a um objetivo de lucro, contribuindo para o descrédito de uma terapia que poderia trazer excelentes resultados.

Estimular e promover a integração dos conhecimentos e técnicas de utilidades comprovadas existentes na medicina oficial e nas alternativas, possibilitando a nível dos órgãos formadores de recursos humanos, a discussão ampla e a possibilidade desse pessoal conhecer essas outras terapêuticas para sua utilização no seu exercício profissional.

STEAGALL-GOMES, D. L. et alii. Alternatives practical medical: the phytoterapie and homeopathy. Rev. Bras. Enf., Brasília, 38(3/4): 329-348, July/Dec. 1985.

\section{REFERÊNCIAS BIBLIOGRÁFICAS}

1. BRASIL. Ministério da Saúde. Ação participativa: capacitação de pessoal. Brasília, Centro de Documentação do Ministério da Saúde, 1982. 35 p.

2. CARLINI, E. A. Éfeitos psicotrópicos de plantas brasileiras: aspectos farmacológicos. Cienc. e Cult., São P’aulo, 35(4):444-50, abr. 1983.

3. Pesquisas com plantas brasileiras usadas em medicina popular. Rev. Ass. Méd. Bras., São Paulo, 29(5/6):109-110, 1983.

4. Homeopatia: ontem, hoje e amanhã. Rev. Ass. Méd. Bras., São Paulo, 29(11/12):2104, 1983.

5. DANTAS, F. O que é a homeopatia. São Paulo, Brasiliense, 1984, 116 p. (Primciros l'assos, 134).

6. FERRARI, B. T. A redescoberta das plantas medicinais. Rev. Bras. Clin. Terap., São Paulo, 13(8): 308-15, ago. 1984.

7. MATOS, F. G. A. Éfeitos psicotrópicos de plantas brasilciras. Aspectos antropológicos. Cienc. $e$ Cult., São Paulo, 35(4):432-4, abr. 1983.

8. MATOS, J. K. A. Plantas medicinais - problemas e possibilidades. Hort. Bras. 1(1):5-10, maio 1983.

9. MEDICINA Popular - uma alternativa de cura e atendimento. FOLHETIM, São Paulu, no 218, 22 mar. $1981.11 \mathrm{p}$.

10. NOGUEIRA, M. J. C. Fitoterapia popular e enferma. gem comunitária. São Paulo, 1983, 257 p. Tese (Livrc Docência) - USP. Escola de Enfermagem.

11. OLIVEIRA, A. B. Efeitos psicotrópicos de plantas brasileiras. Aspectos químicos. Cien. e Cult., São Paulo, 35(4):348-44, abr. 1983.

12. RIZZINI, C. T. Efcitos psicotrópicos de plantas brasileiras - aspectos botânicos. Cien. e Cult. São Paulo, 35(4):434-8, 1983.

13. SCARONE, O. Diabete e plantas medicinais. Rev. Bras. Clin. Terap., São Paulo, 13(8):316, ago. 1984.

14. TERAPIAS alternativas. Planeta, São Paulo, 143:5-7, ago. 1984 . 


\section{UNIVERSIDADE DE SÃO PAULO \\ ESCOLA DE ENFERMAGEM DE RIBEIRÃO PRETO \\ ENFERMAGEM DE SAÚDE PÚBLICA}

\section{O USO DA MEDICINA ALTERNATIVA PELA POPULAÇÃO}

$$
\mathrm{CS}_{1} \text { - INAMPS - EERP }
$$

1. Idade em anos:

2. Estado Civil:

3. Ocupação do entrevistado:

4. Nível de escolaridade:

( ) analfabeto ( ) alfabetizado (último ano cursado do 10 e 29graus).

( ) curso superior: cursando: concluído:

Nome desse curso:

5. Usa alguma planta ou fruto em forma de chá, xarope ou outras formas como remédio para você e família?
a) Não ( )
b) $\operatorname{Sim}($ ) Justifique (Por quê?)

6. A família usa habitualmente chás como bebida?

7. Como ou com quem você aprendeu a usar plantas como medicamento?

8. Onde você consegue essas plantas?

farmácia ( ) no próprio quintal ( ) em casa de vizinho ( ) casa de amigos ( ) casa de parentes ( ) casa de familiares ( )

Outros:

9. Você 'gostaria de aprender a usar plantas como remédio?
a) $\operatorname{Sim}($ )
b) Não ( )

Justifique (Por quê?) 


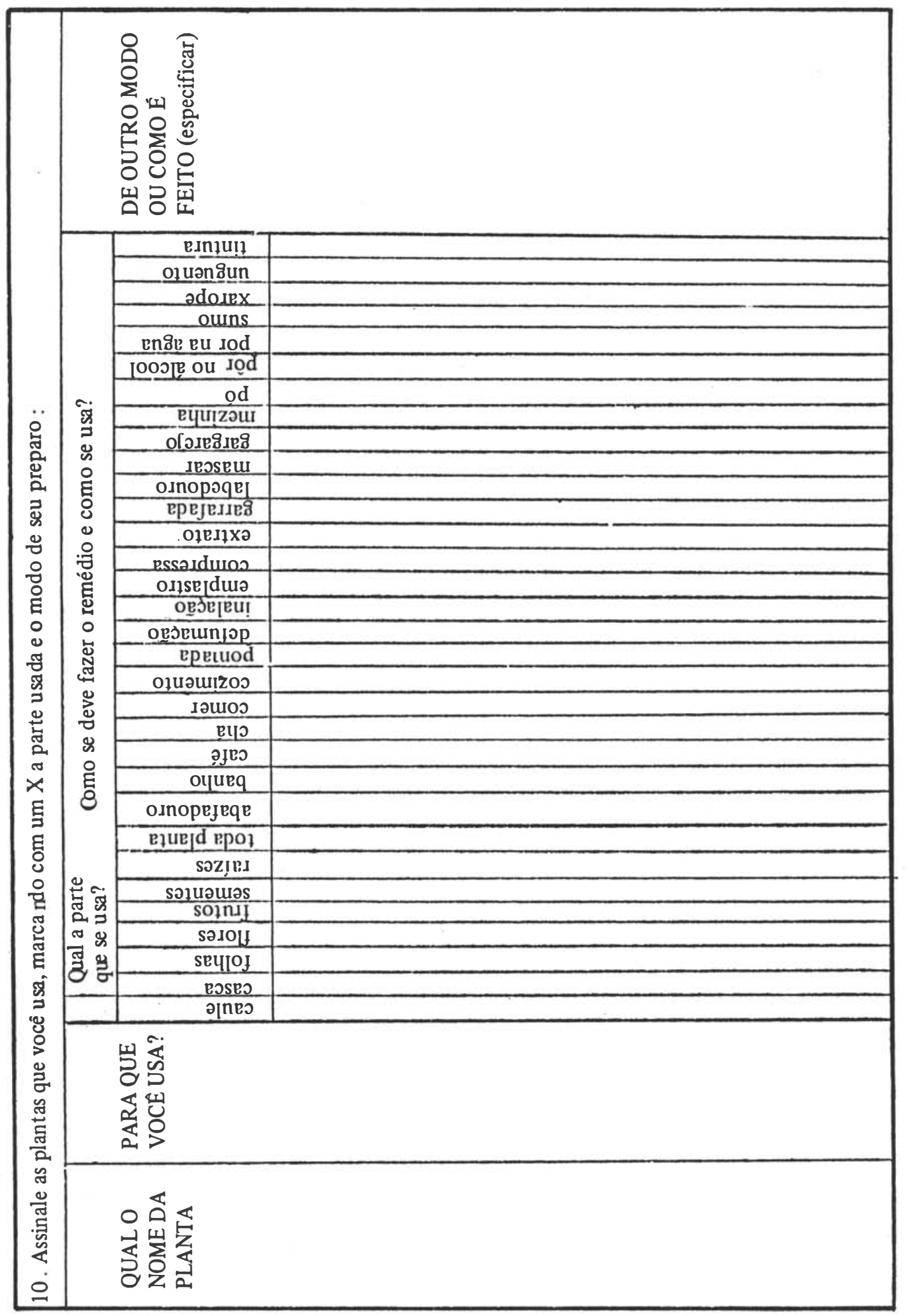




\section{II - TERAPEUTICA HOMEOPÁTICA}

13. Você já ouviu falar num tratamento que se chama "homeopatia"?

Não ( ) $\operatorname{Sim}($ )

Onde foi? (resumir a informação):

12. Você já usou alguma vez remédios da homeopatia?

Não ( ) $\operatorname{Sim}($ )

Qual foi o remédio (nome)?

Para que foi esse remédio?

Quem lhe indicou? (ou como resolveu usá-lo?)

13. Como você adquiriu ou adquire esse medicamento homeopático?

Compra em farmácia ( ) recebe gratuitamente em Instituições ( )

ganhou de vizinhos ( ) da própria casa ( )

ganhou de amigos

Outros:

14. Como você se sentiu ou sente com o tratamento homeopático?

15. Você conhece outras pessoas que usam esse medicamento?

Não（） $\operatorname{Sim}($ Quem é?

16. Gostaria de fazer tratamento com médico homeopata?

Não ( ) Sim ( )

Por quê?

17. Você gostaria de aprender como se usa a homeopatia para tratamentos?

Não ( ) Sim ( )

18. Observações do entrevistador: 